Communications in Physics, Vol. 30, No. 4 (2020), pp. 319-330

DOI:10.15625/0868-3166/30/4/14425

\title{
TUNGSTEN OXIDE NANOPLATES: FACILE SYNTHESIS, CONTROLLABLE OXYGEN DEFICIENCY AND PHOTOCATALYTIC ACTIVITY
}

\author{
VAN THAI NGUYEN ${ }^{1}$, HONG SON NGUYEN ${ }^{1}$, VAN THANG PHAM ${ }^{1}$, \\ T. TUYET MAI NGUYEN ${ }^{2}$, T. LAN ANH LUU ${ }^{1}$, HUU LAM NGUYEN $^{1}$, \\ DUC CHIEN NGUYEN ${ }^{1}$ AND CONG TU NGUYEN ${ }^{1, \dagger}$
}

${ }^{1}$ School of Engineering Physics, Hanoi University of Science and Technology, No 1 Dai Co Viet Street, 100000 Hanoi, Vietnam

${ }^{2}$ School of Chemical Engineering, Hanoi University of Science and Technology, No 1 Dai Co Viet Street, 100000 Hanoi, Vietnam

${ }^{\dagger} E$-mail: tu.nguyencong@hust.edu.vn

Received 19 July 2020

Accepted for publication 7 October 2020

Published 20 October 2020

\begin{abstract}
Monoclinic tungsten oxide $\left(\mathrm{WO}_{3}\right)$ nanoplates were synthesized via a two-step simple process: acid precipitation at room temperature to prepare $\mathrm{WO}_{3} . \mathrm{H}_{2} \mathrm{O}$ nanoplates and annealing at high temperature $\left(400\right.$ and $\left.500^{\circ} \mathrm{C}\right)$ in ambient air to obtain $\mathrm{WO}_{3}$ nanoplates. The effect of annealing temperature on physical properties (morphology, oxygen deficiency, crystallinity, optical properties, and photocatalytic activity) of $\mathrm{WO}_{3}$ nanoplates was studied. At both two studied annealing temperatures, all samples have the stable monoclinic structure and visible light-range optical bandgap, but the morphology and photocatalytic activity of the samples vary significantly with annealing temperature. At higher annealing temperature $\left(500^{\circ} \mathrm{C}\right)$, the sample has both nanoplate and nanograin morphologies with round edges, higher crystallinity, larger optical bandgap $(2.71$ $\mathrm{eV}$ ), and lower photocatalytic activity. The sample annealed at $400^{\circ} \mathrm{C}$ has nanoplate morphology with sharp edges, lower optical bandgap $(2.63 \mathrm{eV})$, and higher photocatalytic which shows a high potential for photocatalytic application under visible light irradiation. The effect of the annealing temperature on the properties of $\mathrm{WO}_{3}$ nanoplates is assigned to the dehydration, the coalescence, and/or the melting processes at high temperatures. Dehydration causes the formation of oxygen vacancy - oxygen deficiency. The coalescence and/or the melting result in the changing of morphology and the decrease of the oxygen vacancies. These results imply a simple, cost-effective method to prepare highly oxygen-deficient $\mathrm{WO}_{3}$ nanoplates.
\end{abstract}

Keywords: tungsten oxide nanoplate, acid precipitation, optical bandgap, photocatalyst, oxygen deficiency.

Classification numbers: 81.16.-c, 81.40.-z, 78.67.Bf.

C2020 Vietnam Academy of Science and Technology 


\section{INTRODUCTION}

Tungsten oxide $\left(\mathrm{WO}_{3}\right)$ is a typical n-type metal oxide semiconductor with a tunable optical bandgap in the range of $2.5-3.2 \mathrm{eV}[1,2]$. Moreover, $\mathrm{WO}_{3}$ is stable in both acid and base environment, harmless to humans, abundant in the Earth, and especially has the electrochromic property $[1,2]$. These properties have made $\mathrm{WO}_{3}$ become one of the most studied metal oxides for various applications such as gas sensors [3], photocatalysis [4], and smart window applications [5]... Recently, the study on $\mathrm{WO}_{3}$ materials is once more blooming for cutting-edge applications such as water splitting, smart window, pathogen control, optoelectronic devices, film-based field-effect transistor, and even surface-enhanced Raman scattering substrate [1,2,6-8]. These cutting-edge applications mainly rely on the high charge transferability of $\mathrm{WO}_{3}$ [6]. The charge transferability of tungsten oxide originates from the crystal structure and the oxygen vacancy on $\mathrm{WO}_{3}$ [6-10]. The crystal structure of tungsten oxide is counted as the assembly of the $\mathrm{WO}_{6}$ octahedra via corner-sharing (monoclinic, hexagonal, cubic, orthorhombic, hexagonal, triclinic, tetragonal phases $-\mathrm{WO}_{3}$ ) and/or edge-sharing (magneli phase - $\mathrm{WO}_{3-x}$ which only appears in the oxygen-deficient environment) arrangements $[1,2,11]$. Note that, at room temperature, monoclinic and hexagonal phases are the most stable phases which are mainly studied for long-term applications $[1,2,11]$. The arrangement of $\mathrm{WO}_{6}$ octahedra creates tunnels through that small ion could intercalate resulting in ion transferability. The electron transferability of $\mathrm{WO}_{3}$ originates from the oxygen vacancy on the surface which could be created via crystal transformation during annealing $[11,12]$ or hydrogen treatment $[13,14]$ or engineering the exposed facets [9]... Due to the limit of the crystal structures (monoclinic or hexagonal structures - two stable structures at room temperature), recently, to enhance the charge transferability of tungsten oxide, the oxygen defect and crystal facet engineering are mainly studied [6,11-14].

For engineering oxygen defects, a widely-used simple method is annealing [11,12]. For engineering crystal facet, the most preferable morphology is a rectangular shape and the preferable facets are (002), (020), and (200) [2]. In particular, for photocatalytic application, Farhadian et al. reported that the $\mathrm{WO}_{3}$ nanoplates have more photocatalytic activity than other morphologies due to having more active sites in the edges and corners [15]. Much other research also shows that monoclinic $\mathrm{WO}_{3}$ nanoplates - which have dominant facets of (002), (020), and (200) - are very promising for many applications such as photocatalyst, gas sensor [16-18].

In this work, the authors aim to use both oxygen defect and crystal facet engineering methods to prepare monoclinic tungsten oxide nanoplates. In detail, we report a two-step simple process to prepare stable monoclinic tungsten oxide nanoplates via acid precipitation at room temperature (RT) and annealing in ambient air, in which, the annealing causes both the crystal transformation and the change of dominant exposed facet. The effect of annealing temperature on the morphology, crystallinity, optical properties, and the oxygen deficiency on the surface of $\mathrm{WO}_{3}$ nanoplates will be discussed through analyzing the field-emission scanning electron microscopy, $\mathrm{X}$-ray diffraction, Raman scattering, and diffuse reflectance data. The photocatalytic activity of samples was evaluated via the degradation measurement of methylene blue (MB) under a quasisun light source. The mechanism of the oxygen vacancy formation is also discussed in detail. 


\section{EXPERIMENT}

\section{II.1. Samples preparation}

In this work, all chemicals were used directly without any further purification. The samples were prepared via the following steps: first, dispersing $8.25 \mathrm{~g}$ of $\mathrm{Na}_{2} \mathrm{WO}_{4} \cdot 2 \mathrm{H}_{2} \mathrm{O}(99.5 \%$, Xilong) into $25 \mathrm{ml}$ of bi-distilled water at RT; adding dropwise $45 \mathrm{~mL}$ of $\mathrm{HCl}(37 \%$ wt., Xilong) into the above solution to create a highly acidic environment $(\mathrm{pH}=-1.1$, measured by Multiparameter $\mathrm{pH}$ meter HI2020-02 Hanna Instrument); stirring the obtained suspension for $4 \mathrm{~h}$ at RT; keeping the stirred suspension in a closed Teflon pot at RT for $48 \mathrm{~h}$ to carry out the acid precipitation process; after $48 \mathrm{~h}$, cleaning the obtained dark-yellow slurry in the Teflon pot with bi-distilled water and filter paper; drying the cleaned slurry at $80^{\circ} \mathrm{C}$ for $24 \mathrm{~h}$ in ambient air, then grinding the dried sample to obtain as-grown sample; annealing the as-grown sample at different temperatures (400 and $500^{\circ} \mathrm{C}$ ) in ambient air for $2 \mathrm{~h}$ to get the annealed samples.

\section{II.2. Samples characterization}

The field-emission scanning electron microscopy (FESEM, JEOL JSM-7600F) was used to study the morphology of samples. The phase and structural parameters were extracted from the X-ray diffraction (XRD) data measured with X'pert Pro (PANalytical) MPD with CuK- $\alpha$ radiation $(\lambda=1.54065 \AA)$. The XRD data was analyzed using the HighScore Plus software using the ICDD database. Micro Raman spectroscopy of samples was observed by Renishaw Invia Raman Microscope using $633 \mathrm{~nm}$ laser. The optical properties of samples were studied by analyzing the absorbance spectra of samples measured by UV-Vis spectrophotometer JASCO V-750 using 60 mm Integrating Sphere ISV-922.

\section{II.3. Photocatalytic activity measurement}

The photocatalytic activity of samples was analyzed through the degradation experiment of methylene blue (MB) at RT. In photocatalytic experiments, $20 \mathrm{mg}$ of catalyst was dispersed in a $100 \mathrm{ml} \mathrm{MB}$ solution (10 ppm) under magnetic stirring to get the testing suspension. The testing suspension was firstly kept in the dark for $30 \mathrm{~min}$ to get an adsorption-desorption equilibrium state. After $30 \mathrm{~min}$ in the dark, the photocatalytic reaction was performed under visible light irradiation using a commercial light source (Compact 250W- Rang Dong, Viet Nam) at RT for 150 mins. To evaluate the MB degradation with testing time, after each 30-min interval, the absorbance of the testing solution was measured using a UV-VIS spectrometer (Varian 100). The efficiency MB degradation was extrapolated from the variation of intensity of the typical 664-nm peak in the absorbance spectra of MB. The efficiency of MB degradation $(\mathrm{H})$ was estimated via the following equation:

$$
H=\frac{C_{0}-C_{t}}{C_{0}} \times 100 \%=\frac{I_{0}-I_{t}}{I_{0}} \times 100 \%,
$$

where $C_{0}(\mathrm{mg} / \mathrm{L})$ and $C_{t}(\mathrm{mg} / \mathrm{L})$ are the concentration of MB in testing solution at the beginning and at time $t$ during the photocatalytic reaction, respectively; $I_{0}$ and $I_{t}$ are the intensity of the $664 \mathrm{~nm}$ peak in absorbance spectra of MB at the beginning and at time $t$, respectively. 


\section{RESULTS AND DISCUSSION}

\section{III.1. FESEM and XRD analysis}

Figure 1a presents the FESEM images of the as-grown sample. The as-grown sample appears to have nanoplate morphology with the mean surface of $\sim 100 \mathrm{~nm} \times 100 \mathrm{~nm}$ and thickness of $\sim 40 \mathrm{~nm}$. Fig. $1 \mathrm{~b}$ presents the XRD pattern of the as-grown sample in comparison with the standard pattern of orthorhombic $\mathrm{WO}_{3} \cdot \mathrm{H}_{2} \mathrm{O}$ (ICDD card No 01-084-0886). The XRD analysis shows that the as-grown sample has an orthorhombic structure, and there is no signal of other phases or impurities in the XRD pattern of the as-grown sample.
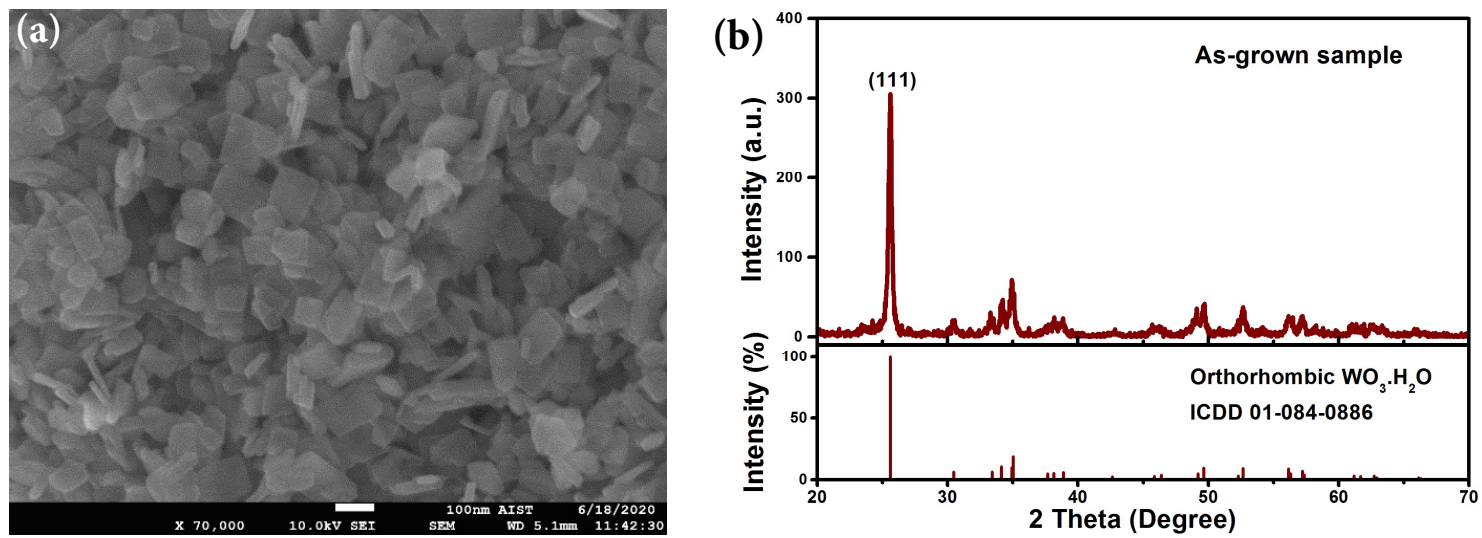

Fig. 1. (a) FESEM images and (b) XRD pattern of the as-grown sample.

The FESEM images of annealed samples are manifested in Fig. 2. The morphology of annealed samples changes in comparison with the as-grown sample. The sample annealed at $400^{\circ} \mathrm{C}$ appears to have nanoplate morphology with the same mean surface with as-grown sample $(\sim 100 \mathrm{~nm} \times 100 \mathrm{~nm})$, but thinner thickness - about $\sim 15^{\circ} \mathrm{nm}$ (Fig. 2a). The change is more critical with the sample annealed at $500^{\circ} \mathrm{C}$ in which the sample not only has the nanoplate morphology with round edges and smaller dimensions but also has nanograin morphology (Fig. 2b). The change of the morphology with annealing temperature, which is also previously reported in the literature [16,19], is assigned to the transformation of crystal structure, the dehydration, the melting, and/or the broken of nanoplate at high temperature $\left(>400^{\circ} \mathrm{C}\right)$.

Figures $3 \mathrm{a}$ and $3 \mathrm{~b}$ present the XRD patterns of annealed samples. The XRD analysis using HighScore Plus software shows that samples annealed at 400 and $500^{\circ} \mathrm{C}$ have XRD patterns similar to the standard XRD patterns ICDD No 01-072-0677 and 01-071-2141 of stable monoclinic $\mathrm{WO}_{3}$, respectively. The crystal parameter of the standard patterns (ICDD No 01-072-0677 and 01-071-2141) are listed in Table 1. At both two studied annealing temperatures $\left(400\right.$ and $\left.500^{\circ} \mathrm{C}\right)$ the stable monoclinic structure was obtained, but at the higher temperature, the crystal structure is slightly more compact - shorter lattice constant, higher density, and higher crystallinity sharper and stronger XRD signal. This result also confirms the transformation from orthorhombic $\mathrm{WO}_{3} \cdot \mathrm{H}_{2} \mathrm{O}$ to monoclinic $\mathrm{WO}_{3}$ during the annealing process. Note that, in the orthorhombic structure the strongest peak originates from the plane (111) at $2 \theta=25.62^{\circ}$, meanwhile, in the monoclinic structure the strongest signal originate from three planes (002), (020), and (200) at 

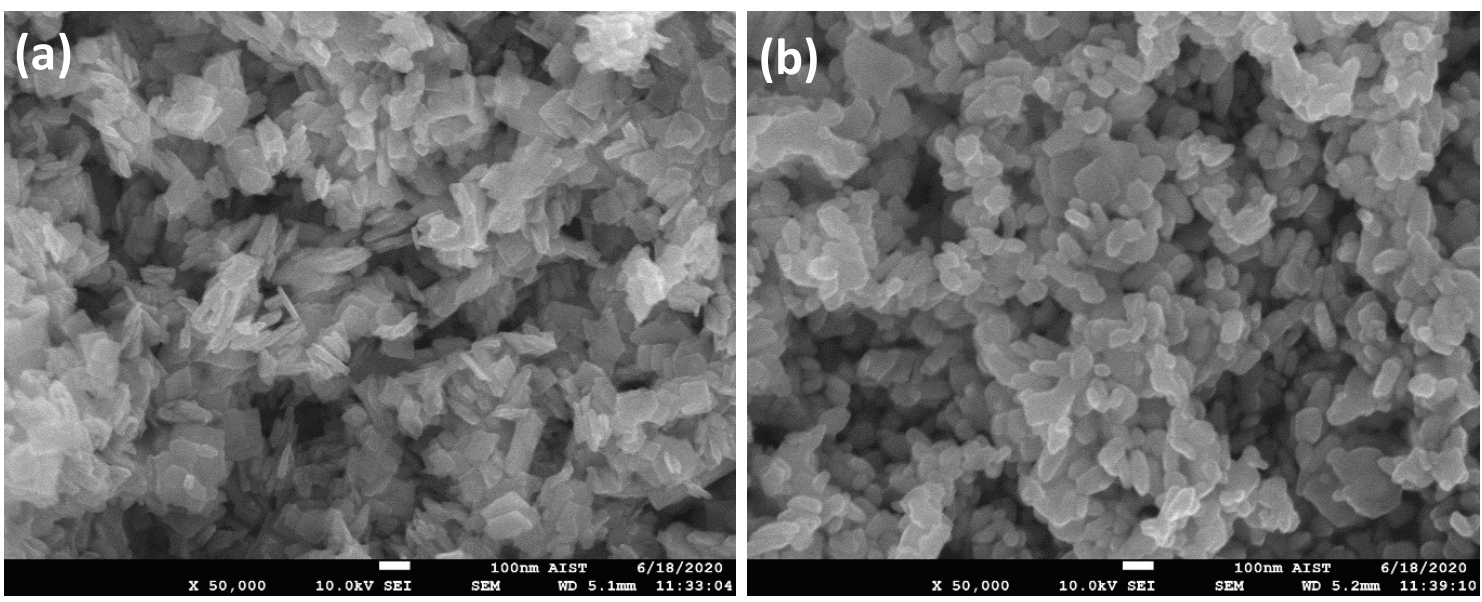

Fig. 2. FESEM images of samples annealed at (a) $400^{\circ} \mathrm{C}$ and (b) $500^{\circ} \mathrm{C}$.

$2 \theta \approx 23.14,23.61$ and $24.38^{\circ}$, respectively, which have higher surface energy and are preferable for photocatalytic applications $[9,18,20,21]$. The change from orthorhombic structure to the monoclinic structure when annealing at high temperature (higher than $300^{\circ} \mathrm{C}$ ) was explained due to dehydration $[22,23]$ which will be mentioned later.

To study the effect of annealing temperature on the crystal structure, the authors use the Williamson - Hall equation [24, 25]:

$$
\beta \cos \theta=\frac{0.9 \lambda}{d}+2 \varepsilon \sin \theta
$$

where $\beta$ is the full width at half maximum of the peak at the diffraction angle $2 \theta, \theta$ is the diffraction angle, $\gamma$ is X-ray wavelength, $\varepsilon$ is the microstrain, and $d$ is the average crystallite size. The average crystalline size and the microstrain in the samples were extrapolated from the plot $(\beta * \cos \theta)$ vs. $(\sin \theta)$ which are presented in Table 1 . The results in Table 1 show that when the annealing temperature increases from 400 to $500^{\circ} \mathrm{C}$, the average crystalline size increases four times, while the microstrain increases more than two times. The increase of both average crystalline size and microstrain is assigned to the crystal transformation of $\mathrm{WO}_{3}$ to get a more stable structure which agrees with XRD analysis using HighScore Plus software.

Table 1. Structural parameters of samples extracted from XRD analysis.

\begin{tabular}{|c|c|c|c|c|c|c|c|c|c|c|c|}
\hline \multirow{2}{*}{ Sample } & \multirow{2}{*}{ ICDD \# } & \multirow{2}{*}{ Structure } & \multicolumn{6}{|c|}{ Structural parameters } & Crystalline size & Microstrain \\
\cline { 5 - 12 } & & $\begin{array}{c}\mathrm{a} \\
(\AA)\end{array}$ & $(\AA)$ & $\begin{array}{c}\mathrm{c} \\
(\AA)\end{array}$ & $\begin{array}{c}\alpha \\
\left({ }^{\circ}\right)\end{array}$ & $\begin{array}{c}\beta \\
\left({ }^{\circ}\right)\end{array}$ & $\begin{array}{c}\gamma \\
\left({ }^{\circ}\right)\end{array}$ & $\begin{array}{c}\rho \\
\left(\mathrm{g} / \mathrm{cm}^{3}\right)\end{array}$ & $\begin{array}{c}\mathrm{d} \\
(\mathrm{nm})\end{array}$ & $\begin{array}{c}\varepsilon \\
(\%)\end{array}$ \\
\hline 400 & $01-072-0677$ & Monoclinic & 7.306 & 7.54 & 7.692 & 90 & 90.881 & 90 & 7.27 & 19.5 & 0.47 \\
\hline 500 & $01-071-2141$ & Monoclinic & 7.297 & 7.539 & 7.688 & 90 & 90.91 & 90 & 7.28 & 79.3 & 1.06 \\
\hline
\end{tabular}



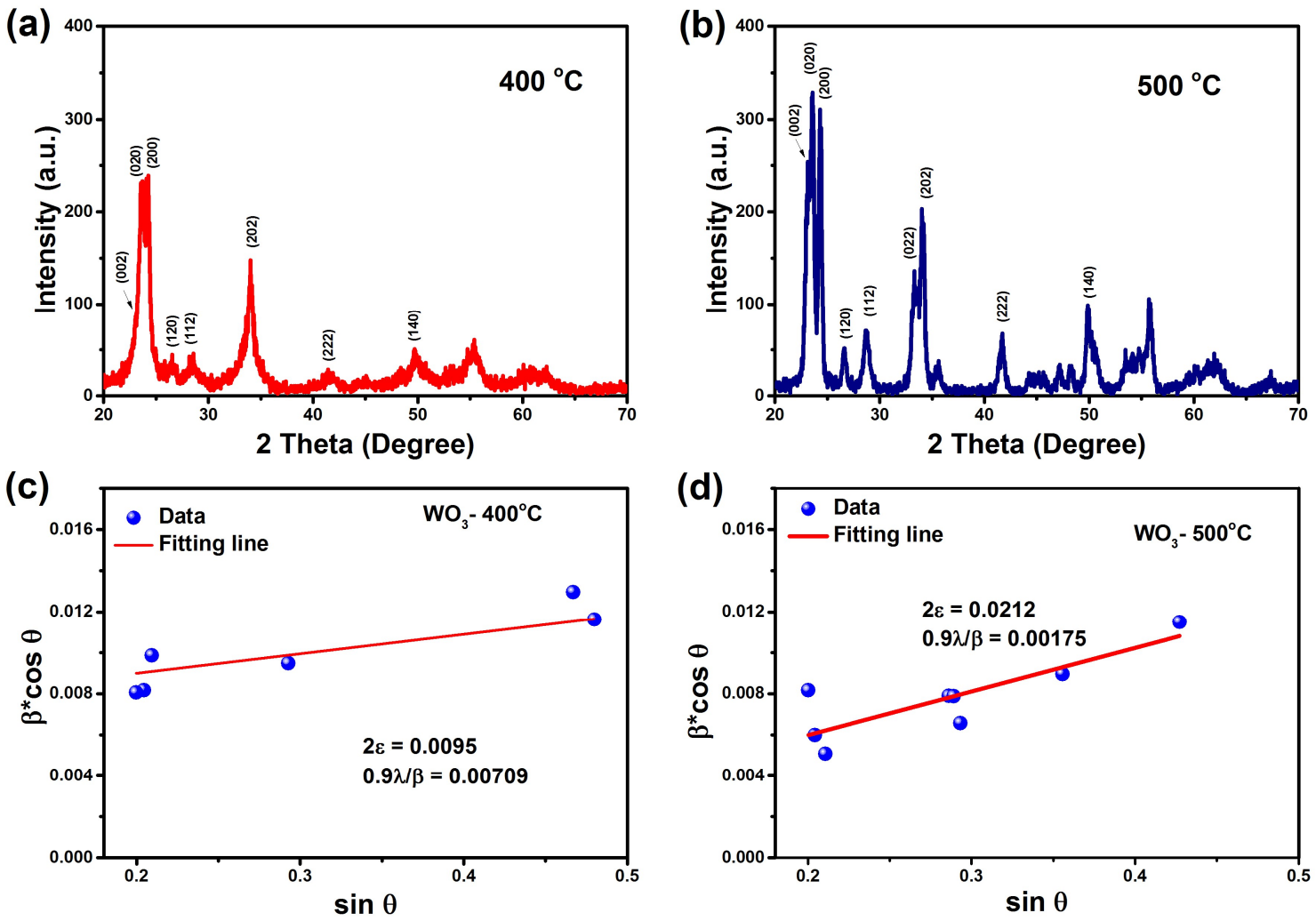

Fig. 3. XRD patterns of samples annealed at (a) $400^{\circ} \mathrm{C}$ and (b) $500^{\circ} \mathrm{C}$; Williamson-Hall plots of samples annealed at (c) $400^{\circ} \mathrm{C}$ and (d) $500^{\circ} \mathrm{C}$.

The formation of orthorhombic $\mathrm{WO}_{3} \cdot \mathrm{H}_{2} \mathrm{O}$ nanoplate structure, the transformation from orthorhombic to monoclinic, and the stabilization of the monoclinic structure were explained in our previous work [26], in which, the formation of $\mathrm{WO}_{3} \cdot \mathrm{H}_{2} \mathrm{O}$ nanoplates was explained via the appearance of the highly acidic environment. In the beginning, the neutral tungstic acid was produced from the acidification of tungstate $\left(\mathrm{WO}_{4}\right)^{2+}$ :

$$
\mathrm{Na}_{2} \mathrm{WO}_{4}+2 \mathrm{HCl} \longrightarrow 2 \mathrm{NaCl}+\mathrm{H}_{2} \mathrm{WO}_{4} \text {. }
$$

The tungstic acid $\mathrm{H}_{2} \mathrm{WO}_{4}$ has both weakly acidic and base properties. In strong acidic environments, it shows the weak-base properties, in which $\mathrm{H}_{2} \mathrm{WO}_{4}$ molecules will interact with water molecules and form the complex structure $\left[\mathrm{WO}(\mathrm{OH})_{4}\left(\mathrm{OH}_{2}\right)\right][27]$ :

$$
\mathrm{H}_{2} \mathrm{WO}_{4}+2 \mathrm{H}_{2} \mathrm{O} \stackrel{\text { Solvent, High }\left[\mathrm{H}^{+}\right]}{\longrightarrow}\left[\mathrm{WO}(\mathrm{OH})_{2}(\mathrm{OH})_{2}\left(\mathrm{OH}_{2}\right)\right]^{0} \text {. }
$$

In a highly acidic environment, this complex structure will aggregate to form $\mathrm{WO}_{3} \cdot \mathrm{H}_{2} \mathrm{O}$ nanoplate [27]. When annealing at high temperature $\left(400\right.$ and $\left.500^{\circ} \mathrm{C}\right)$, the dehydration ${ }^{\circ} \mathrm{Ccurs}$ as the following reaction $[22,23,26]$ :

$$
\mathrm{H}_{2} \mathrm{WO}_{4} \stackrel{\text { Dehydration }}{\longrightarrow} \mathrm{H}_{2} \mathrm{O}+\mathrm{WO}_{3} \text {. }
$$


The dehydration causes the decomposition of a water molecule between $\mathrm{WO}_{3} \cdot \mathrm{H}_{2} \mathrm{O}$ layers which results in the delamination of thick $\mathrm{WO}_{3} \cdot \mathrm{H}_{2} \mathrm{O}$ nanoplate into thinner $\mathrm{WO}_{3}$ nanoplate at $400^{\circ} \mathrm{C}$ (Fig. 2a). At higher temperatures, the delamination happens stronger and the melting appears. The stronger delamination causes the breaking of $\mathrm{WO}_{3}$ nanoplates into smaller plates. The melting causes the rounding of the nanoplates (as observed in Fig. 2b). Besides that, at higher annealing temperature, molecules re-organize to form a higher crystallinity structure (higher XRD intensity) which has the larger average crystalline size, higher microstrain, higher compactness higher mass density and shorter lattice constant.

\section{III.2. Raman spectroscopy analysis}

Because the micro Raman spectroscopy is sensitive to the molecular arrangement, Raman spectroscopy is used to study the variety of oxygen vacancies on the surface and even the crystal transformation of the sample [22,28-30]. Fig. 4 shows the Raman spectra of all samples measured under the same condition (excitation power $-3 \mathrm{~mW}$ ). In the Raman spectra of the as-grown sample, two characteristic peaks at $\sim 946$ and $640 \mathrm{~cm}^{-1}$ of orthorhombic $\mathrm{WO}_{3} \cdot \mathrm{H}_{2} \mathrm{O}$ are observed which accords with the XRD result. Two peaks at $\sim 946 \mathrm{~cm}^{-1}$ and $640 \mathrm{~cm}^{-1}$ are corresponding to the $\mathrm{W}^{6+}=\mathrm{O}$ and $\mathrm{O}-\mathrm{W}^{6+}-\mathrm{O}$ bindings in $\mathrm{WO}_{3} \cdot \mathrm{H}_{2} \mathrm{O}$, respectively [31,32]. After annealing at 400 and $500^{\circ} \mathrm{C}$, the change of the Raman pattern accords with the change of crystal structure from orthorhombic to monoclinic phase [20,33]. The characteristic peaks of the monoclinic $\mathrm{WO}_{3}$ at $269.4,326.5,710.8$, and $806.6 \mathrm{~cm}^{-1}$ are observed in the Raman spectra of two annealed samples $[24,30]$. The peaks at 269.4 and $326.5 \mathrm{~cm}^{-1}$ are corresponding to bending vibrations, the peaks at 710.8 and $806.6 \mathrm{~cm}^{-1}$ are corresponding to stretching vibrations of $\mathrm{W}-\mathrm{O}$ binding in monoclinic $\mathrm{WO}_{3}$. Note that, the characteristic peak at $710.8 \mathrm{~cm}^{-1}$ in the sample annealed at $400^{\circ} \mathrm{C}$ is red shifted to $715.7 \mathrm{~cm}^{-1}$ in sample annealed at $500^{\circ} \mathrm{C}$ which implies the expansion of W-O bindings on the surface. This expansion of $\mathrm{W}-\mathrm{O}$ binding is explained by the decrease of oxygen vacancies due to the transformation of $\mathrm{WO}_{3}$ during the annealing process $[12,22,34,35]$.

The Raman data also implies the effect of annealing temperature on the crystallinity of the sample. The crystal structure first changes from the orthorhombic to monoclinic when annealing at $400^{\circ} \mathrm{C}$ with the dehydration and delamination process. The decomposition of water molecules at this temperature results in the formation of dangling bonds which act as oxygen vacancies. The formation of the dangling bonds is confirmed by the appearance of the wide shoulder at $\sim 640 \mathrm{~cm}^{-1}$ in Raman spectra of the sample annealed at $400^{\circ} \mathrm{C}$ which causes the asymmetry of two peaks at 710.8 and $806.6 \mathrm{~cm}^{-1}$. When the annealing temperature increases to $500^{\circ} \mathrm{C}$, the Raman signal becomes remarkably sharper and stronger. The

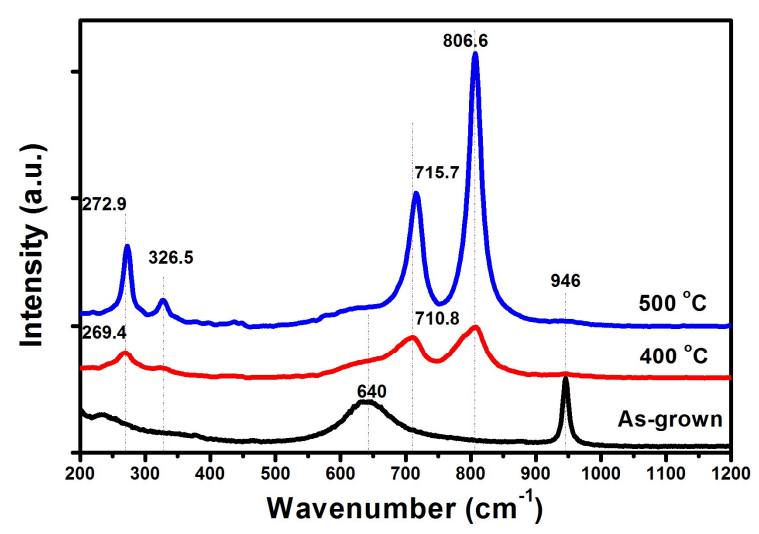

Fig. 4. Raman spectra of as-grown and annealed samples. full width at half maximum of two characteristic peaks of monoclinic $\mathrm{WO}_{3}$ at 710.8 and 806.6 $\mathrm{cm}^{-1}$ decreases significantly from 54.6 and $56.3 \mathrm{~cm}^{-1}$ to 29.2 and $29.0 \mathrm{~cm}^{-1}$ when the annealing 
temperature increases from 400 to $500^{\circ} \mathrm{C}$, respectively. The sharper and stronger Raman signal confirms the more compact arrangement and the higher crystallinity of $\mathrm{WO}_{3}$ annealed at $500^{\circ} \mathrm{C}$. Besides that, the oxygen in ambient air gets to the surface of $\mathrm{WO}_{3}$ and reduces the oxygen vacancies during the coalescence of $\mathrm{WO}_{3}$ on the surface.

\section{III.3. Optical properties}

Figure 5(a) exhibits the absorption spectra of samples. It appears that the edge of the absorbance spectra of samples is blue-shifted under the annealing process. The higher the annealing temperature, the further shift. The shift is assigned to the transformation from orthorhombic $\mathrm{WO}_{3} \cdot \mathrm{H}_{2} \mathrm{O}$ to monoclinic $\mathrm{WO}_{3}[20,33]$. From absorbance data, the optical bandgap of samples is extrapolated using the method proposed by Das et al in which the relation between absorption coefficient $\alpha$ and the incident photon energy $h v$ is expressed as follows:

$$
\frac{d(\alpha h v)}{d(h v)}=\frac{n}{h v-E_{g}},
$$

where $\alpha$ is the absorption coefficient calculated from absorbance $k$ via the formula: $\alpha=4 \pi k / \lambda$ in which $\lambda$ is the wavelength of the incident photon; $h v$ is the incident photon energy; $n=1 / 2,2$ for the direct, in-direct allowed recombination, respectively; $B$ is an arbitrary coefficient; $E_{g}$ is the optical bandgap of the sample [24,36,37]. Via this relation, the optical bandgap of samples was extracted from the plot of $[d(\ln (\alpha h v)) / d(h v)]$ versus $h v$ without depending on the value of $n$ as Tauc's method [24,36,37].

Figures 5 (b-d) present the plots of $[d(\ln (\alpha h v)) / d(h v)]$ versus $h v$ and extracted optical bandgap of as-grown and annealed samples. The results show that all-optical bandgap values are in the visible range and the optical bandgap increase with annealing temperature. The increase of the optical bandgap accords with the change of structure from orthorhombic to monoclinic, which is also reported by Sanasi et al. [35]. But opposite to the result reported by Sanasi et. al., when annealed at $500^{\circ} \mathrm{C}$, the optical bandgap of the sample increases to $2.71 \mathrm{eV}$. This increase is explained mainly by the decrease of the oxygen vacancies due to the oxidation during the annealing at high temperature. In this case, when the annealing temperature increases from 400 to $500^{\circ} \mathrm{C}$, the crystal structure changes, and oxidation becomes stronger which reduces the number of oxygen vacancies and the carrier concentration - accords with the Raman result, ultimately increasing the optical bandgap. 3.5 Photocatalytic properties Photocatalytic properties of annealed samples were studied through the degradation efficiency of MB dyes under visible light irradiation. Fig. 6a and $\mathrm{b}$ show the absorption spectra of testing solution using samples annealed at $400^{\circ} \mathrm{C}$ and $500^{\circ} \mathrm{C}$ as the catalyst at different times. The decrease of the absorption intensity with irradiation time reveals the degradation of the MB dye under visible light irradiation. Note that the decrease of the absorption intensity of testing solution using sample annealed at $400^{\circ} \mathrm{C}$ is more pronounced than the one using sample annealed at $500^{\circ} \mathrm{C}$. As shown in Fig. 6c, after 30 mins in the dark for adsorption-desorption equilibrium and $150 \mathrm{~min}$ under irradiation, the degradation efficiencies are $51 \%$ and $33 \%$ for samples annealed at 400 and $500{ }^{\circ} \mathrm{C}$, respectively. This result clearly shows that the sample annealed at $400^{\circ} \mathrm{C}$ has similar absorptivity but higher photocatalytic activity than the sample annealed at $500^{\circ} \mathrm{C}$. The decrease of photocatalytic activity with annealing temperature is attributed to the larger optical bandgap, the higher crystallinity, the coalescence of samples, and the decrease of the oxygen vacancies. Larger optical band gap causes lower light absorption. The 
(a)
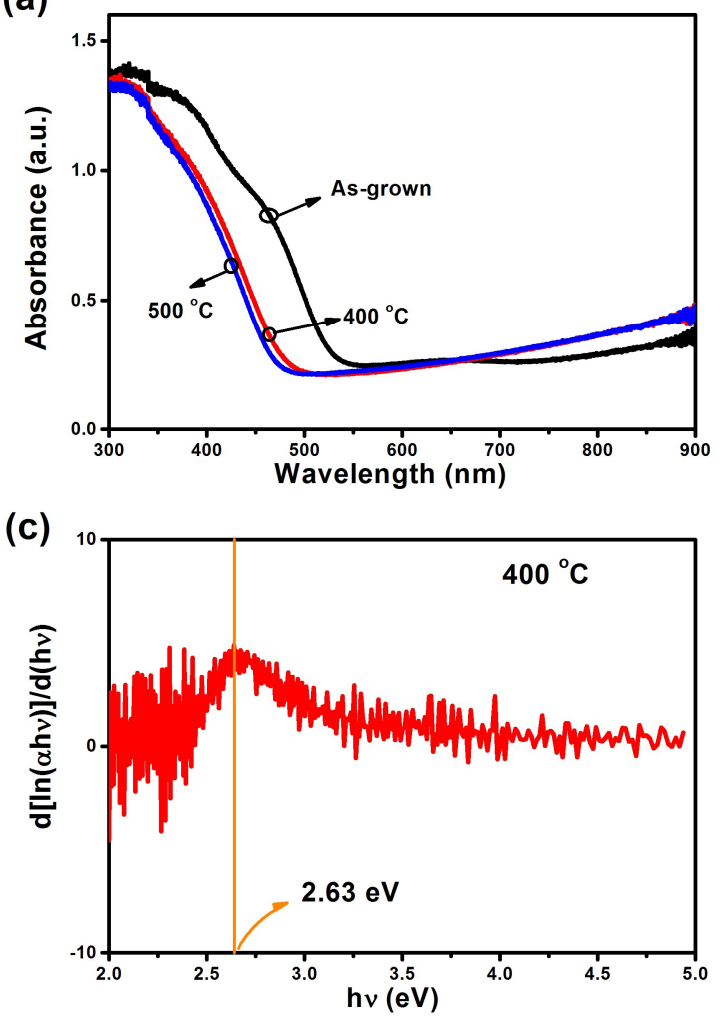

(b)

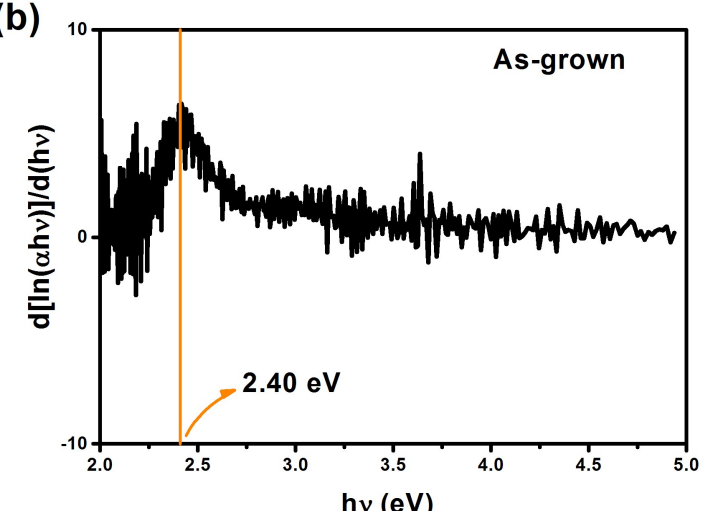

(d)

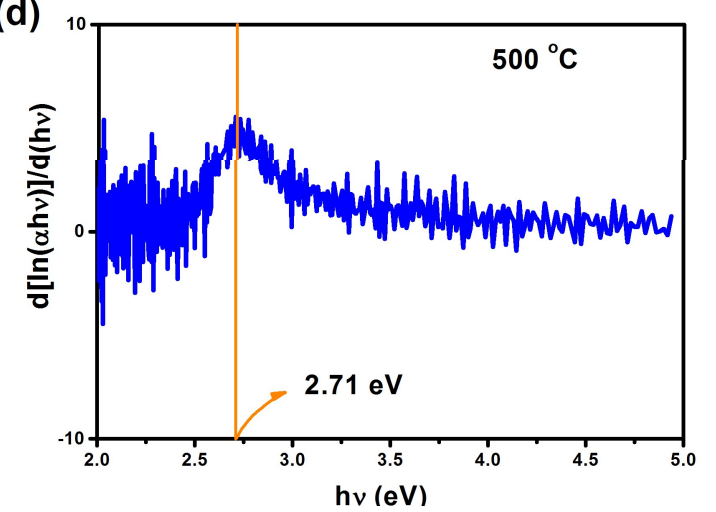

Fig. 5. (a) Absorption spectra of all samples; the plot of $[d(\ln (\alpha h v)) / d(h v)]$ versus $h v$ of (b) as-grown sample, (c) sample annealed at $400^{\circ} \mathrm{C}$, and (d) sample annealed at $500^{\circ} \mathrm{C}$.

higher crystallinity leads to the lower electron-hole recombination rate which would bring about an increase of photocatalytic activity of the sample. On the other hand, the rounder edge originated from the melting of $\mathrm{WO}_{3}$ at high temperature and the decrease of the oxygen vacancies results in the less active sites on the surface of $\mathrm{WO}_{3}$. Apparently, the last effect is stronger leading to the relative decrease of the activity of sample annealed at $500^{\circ} \mathrm{C}$.

Many researchers have confirmed that the photo-oxidation kinetics model of dyes accords with the Langmuir-Hinshelwod kinetic expression [38]. Fig. 6d shows the related kinetics data over the catalysts under visible light irradiation. It can be seen that the regression curve of the natural logarithm of normalized MB concentration versus reaction time approximates linear, indicating that the kinetics of $\mathrm{MB}$ degradation over the photocatalysts follows first-order reaction kinetics [39]:

$$
\ln \left(C / C_{0}\right)=k_{\text {app }} t
$$

where $C$ is the concentration of solute remaining in the solution at irradiation time $t$ and $C_{0}$ is the initial concentration at $t=0, k_{\text {app }}$ denotes the degradation rate constant that determines the photocatalytic activity. The correlation coefficients $R^{2}$ are 0.981 and 0.953 for $\mathrm{WO}_{3}$ samples annealed at $400^{\circ} \mathrm{C}$ and $500^{\circ} \mathrm{C}$, respectively, attesting that the straight lines fit experimental data well. The value of $k_{a p p}$ is calculated by the slope of the linear plot. From Fig. 6d, the extracted 
(a)

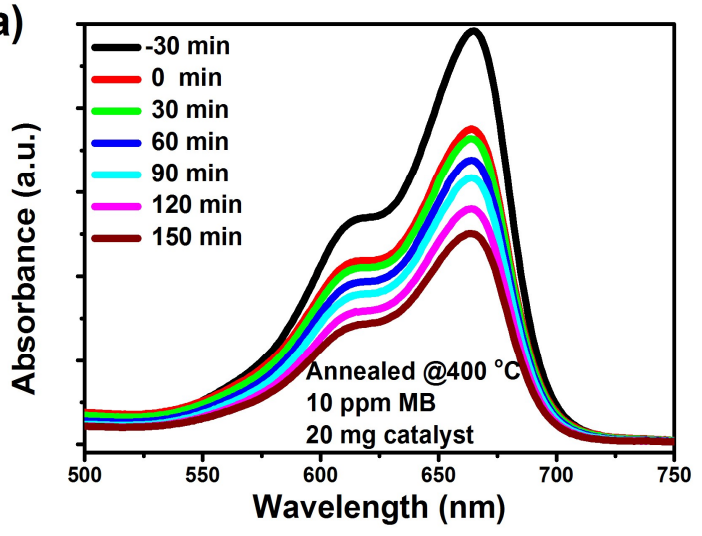

(c)

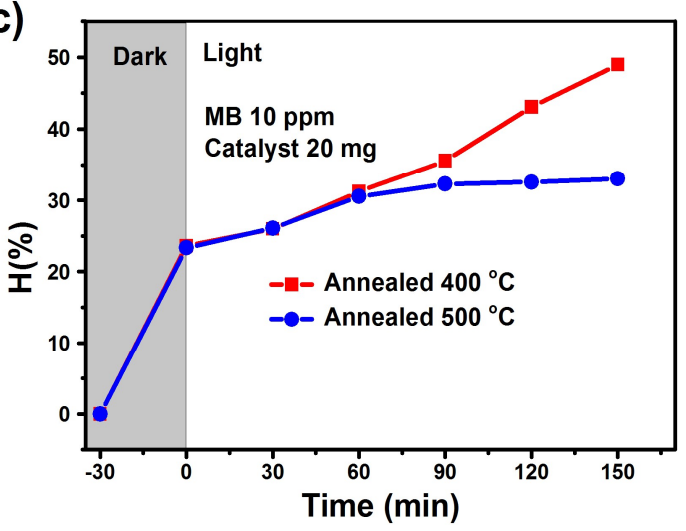

(b)

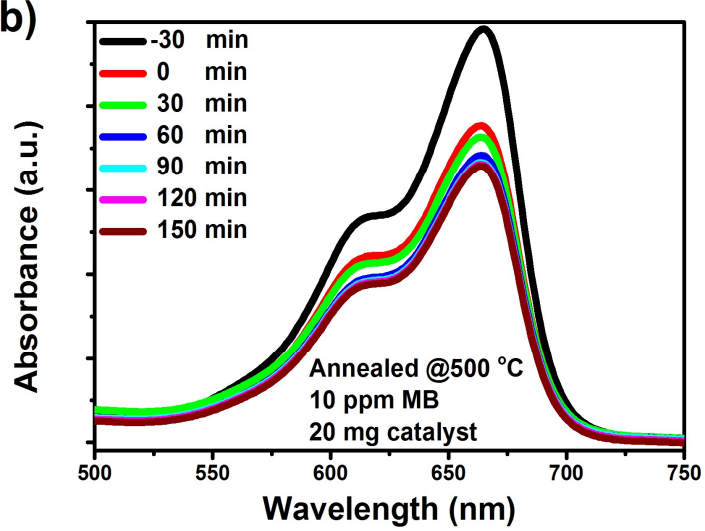

(d)

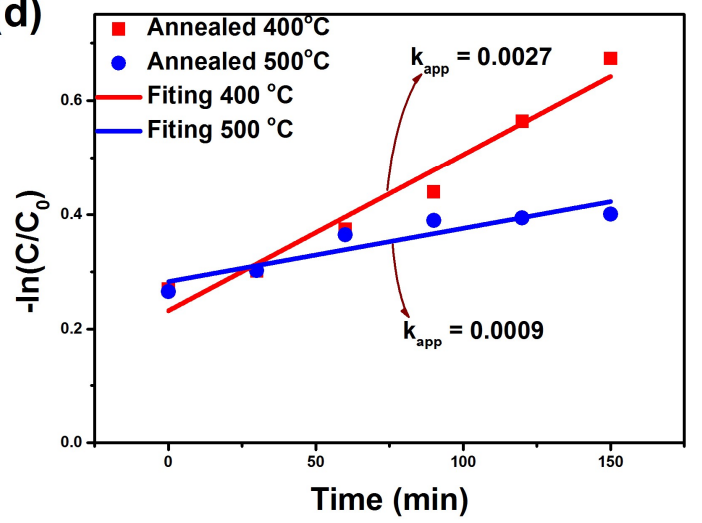

Fig. 6. The absorption spectra of $\mathrm{MB}$ as a function of irradiation time using sample annealed at (a) $400^{\circ} \mathrm{C}$ and (b) $500^{\circ} \mathrm{C}$ as catalysts; (c) The evolution of MB concentration with the reaction time; and (d) the related kinetics data over the catalysts under visible light irradiation.

value of kapp sample annealed at 400 and $500^{\circ} \mathrm{C}$ are 0.0027 min- 1 and $0.0009 \mathrm{~min}^{-1}$, respectively. The photocatalytic activity of sample annealed at $400^{\circ} \mathrm{C}$ is very promising in comparison with the recently reported studies on $\mathrm{WO}_{3}$ - based photocatalyst [40-44]. Table 2 present the $\mathrm{MB}$ degradation efficiencies of $\mathrm{WO}_{3}$-based photocatalyst. All these works were carried out during the same time $(180 \mathrm{~min})$ with similar $\mathrm{MB}$ concentration. It is clear that the MB degradation efficiencies of $\mathrm{WO}_{3}$ nanoplate - sample annealed at $400^{\circ} \mathrm{C}$ - are comparable with the $\mathrm{BiFeO}_{3}$ $\mathrm{WO}_{3}$ nanoparticles composite [40], $\mathrm{WO}_{3}$ nanoparticles [41], $\mathrm{WO}_{3} / g-\mathrm{C}_{3} \mathrm{~N}_{4}$ nanocorals (3:1) composite [42], $10 \% \mathrm{Gr} / \mathrm{WO}_{3}$ nanosticks composite [43], $2 \%$ Eu-doped $\mathrm{WO}_{3}$ nanorods [44] which all required complicated preparation process. Moreover, the $\mathrm{WO}_{3}$ nanoplate catalyst requires a lower concentration - $0.20 \mathrm{~g} / \mathrm{l}$ - than in other works. In detail, Subramanian et al. [40], Huang et al. [41], and Tahir et al. [44] used catalyst concentration of $1.00 \mathrm{~g} / \mathrm{l}$ - five times larger, Singh et al. [42] used catalyst concentration of $0.50 \mathrm{~g} / \mathrm{l}$ - two times larger. Gan et al. [43] used similar catalyst concentrations $-0.25 \mathrm{~g} / \mathrm{l}$ - but the degradation efficiency is lower than the results obtained with the $\mathrm{WO}_{3}$ nanoplate. These results show that the sample annealed at $400^{\circ} \mathrm{C}$ is a promising candidate for visible-light photocatalytic applications. 
Table 2. Comparison of $\mathrm{MB}$ degradation efficiencies of $\mathrm{WO}_{3}$-based photocatalysts.

\begin{tabular}{|l|c|c|c|c|c|c|c|}
\hline \multicolumn{1}{|c|}{ Material } & $\begin{array}{c}\text { Catalyst } \\
(\mathrm{mg})\end{array}$ & $\begin{array}{c}\text { Volume } \\
(\mathrm{ml})\end{array}$ & $\begin{array}{c}\text { Catalyst } \\
\text { concentration } \\
(\mathrm{g} / \mathrm{l})\end{array}$ & $\begin{array}{c}\text { MB } \\
(\mathrm{ppm})\end{array}$ & $\begin{array}{c}\text { Testing } \\
\text { time } \\
(\mathrm{min})\end{array}$ & $\begin{array}{c}\mathrm{H} \\
(\%)\end{array}$ & Ref. \\
\hline $\mathrm{BiFeO}_{3}-\mathrm{WO}_{3}$ nanoparticles & 10 & 10 & 1.00 & 10 & 180 & 54 & {$[40]$} \\
$\mathrm{WO}_{3}$ nanoparticles & 10 & 10 & 1.00 & 10 & 180 & 49 & {$[40]$} \\
$\mathrm{WO}_{3}$ nanoparticles & 100 & 100 & 1.00 & 10 & 180 & 58 & {$[41]$} \\
$\mathrm{WO}_{3} / \mathrm{g}_{-} \mathrm{C}_{3} \mathrm{~N}_{4}$ nanocorals $(3: 1)$ & 5 & 10 & 0.50 & 5 & 180 & 40 & {$[42]$} \\
$\mathrm{WO}_{3}$ nanocorals & 5 & 10 & 0.50 & 5 & 180 & 10 & {$[42]$} \\
$\mathrm{WO}_{3}$ nanopellets & 50 & 200 & 0.25 & 10 & 180 & 5 & {$[43]$} \\
$1 \% \mathrm{Gr} / \mathrm{WO}_{3}$ nanosticks & 50 & 200 & 0.25 & 10 & 180 & 41 & {$[43]$} \\
$10 \% \mathrm{Gr} / \mathrm{WO}_{3}$ nanosticks & 50 & 200 & 0.25 & 10 & 180 & 42 & {$[43]$} \\
$\mathrm{WO}_{3}$ Nano-belts/rods & 100 & 100 & 1.00 & 10 & 180 & 10 & {$[44]$} \\
$2 \%$ Eu-doped $\mathrm{WO}_{3}$ Nano-belts/rods & 100 & 100 & 1.00 & 10 & 180 & 50 & {$[44]$} \\
$\mathrm{WO}_{3}$ nanoplate (annealed at $\left.400^{\circ} \mathrm{C}\right)$ & 20 & 100 & 0.20 & 10 & 180 & 49 & This work \\
\hline
\end{tabular}

\section{CONCLUSION}

Stable monoclinic $\mathrm{WO}_{3}$ nanoplates were simply prepared by a two-step process, i.e. acid precipitation at RT and annealing at high temperature. In two studied annealing temperatures (400 and $500^{\circ} \mathrm{C}$ ), samples all have monoclinic structure, optical bandgap in the visible light range, good photocatalytic activity but the morphology and photocatalytic activity of samples vary remarkably with annealing temperature. At annealing temperature of $400^{\circ} \mathrm{C}$, the sample has nanoplate morphology with sharp edges. When the annealing temperature increases to $500^{\circ} \mathrm{C}$, due to the stronger dehydration, the coalescence, and/or the melting at high temperature, the sample has both nanoplate and nanograin morphologies with higher crystallinity but having rounded edges, smaller dimensions, less oxygen deficiency, and less active sites on the surface. The decrease of oxygen deficiency, furthermore, causes the increase of the optical bandgap from $2.63 \mathrm{eV}\left(400^{\circ} \mathrm{C}\right)$ to $2.71 \mathrm{eV}\left(500^{\circ} \mathrm{C}\right)$. All the changes ultimately result in the lower photocatalytic activity of the sample annealed at $500^{\circ} \mathrm{C}$ in comparison with the sample annealed at $400^{\circ} \mathrm{C}$. These results show that the sample annealed at $400^{\circ} \mathrm{C}$ is a promising material for photocatalytic applications under visible light irradiation. Moreover, the simple two-step preparation process appears to be a costeffective method to manipulate both crystal, optical properties, oxygen deficiency, and exposed facet of tungsten oxide for various applications.

\section{ACKNOWLEDGEMENTS}

This research was funded by the Vietnam Ministry of Education and Training under Grant number B2020-BKA-19. The authors thank the support from the BKEMMA at the AIST-HUST for the FESEM work.

\section{REFERENCES}

[1] Z. Hai, Z. Wei, C. Xue, H. Xu and F. Verpoort, J. Mater. Chem. C. 7 (2019) 12968.

[2] P. Dong, G. Hou, X. Xi, R. Shao and F. Dong, Environ. Sci. Nano. 4 (2017) 539.

[3] X. V. Le, T. L. A. Luu, H. L. Nguyen, C. T. Nguyen, Vacuum. 168 (2019) 108861. 
[4] M. Parthibavarman, M. Karthik, S. Prabhakaran, Vacuum. 155 (2018) 224.

[5] C. Yan, W. Kang, J. Wang, M. Cui, X. Wang, C. Y. Foo, K. J. Chee and P. S. Lee, ACS Nano 8 (2014) 316.

[6] S. Cong, Z. Wang, W. Gong, Z. Chen, W. Lu, J. R. Lombardi, Z. Zhao, Nat. Commun. 10 (2019) 678.

[7] L. Sun, Y. Wang, R. Fazal, Y. Qu, L. Bai and L. Jing, Sci. Rep. 7 (2017) 1303.

[8] H. Kalhori, M. Coey, I. A. Sarsari, K. Borisov, B. Porter, G. Atcheson, M. Ranjbar, H. Salamati and P. Stamenov, Sci. Rep. 7 (2017) 12253.

[9] Y. Li, Z. Tang, J. Zhang and Z. Zhang, J. Alloys Compd. 708 (2017) 358.

[10] Y. Li, C. Wang, H. Zheng, F. Wan, F. Yu, X. Zhang, Y. Liu, Appl. Surf. Sci. 391 (2017) 654.

[11] A. Al Mohammad and M. Gillet, Thin Solid Films 408 (2002) 302.

[12] S. S. Kalanur, I. Yoo, I. Cho and H. Seo, Electrochim. Acta 296 (2019) 517.

[13] T. Singh, R. Müller, J. Singh and S. Mathur, Appl. Surf. Sci. 347 (2015) 448.

[14] I. M. Szilágyi, B. Fórizs, O. Rosseler, Á. Szegedi, P. Németh, P. Király, G. Tárkányi, B. Vajna, K. VargaJosepovits, K. László, A.L. Tóth, P. Baranyai, M. Leskel a, J. Catal. 294 (2012) 119.

[15] M. Farhadian, P. Sangpout, G. Hosseinzadeh, J. Energy Chem. 24 (2015) 171.

[16] H. Zhang, J. Yang, D. Li, W. Guo, Q. Qin, L. Zhu, W. Zheng, Appl. Surf. Sci. 305 (2014) 274.

[17] C. W. Lai, J. Nanomater. 2015 (2015) 563587.

[18] W.-H. Hu, G.-Q. Han, B. Dong, C.-G. Liu, J. Nanomater. 2015 (2015) 346086.

[19] J. Ram, R. G. Singh, R. Gupta, V. Kumar, F. Singh, R. Kumar, J. Electron. Mater. 48 (2019) 1174.

[20] X. V. Le, V. T. Duong, L. A. Luu Thi, V. T. Pham, H. L. Nguyen and C. T. Nguyen, J. Met. Mater. Miner. 29 (2019) 61.

[21] M. D’Arienzo, L. Armelao, C. M. Mari, S. Polizzi, R. Ruffo, R. Scotti and F. Morazzoni, RSC Adv. 4 (2014) 11012.

[22] M. Ahmadi, S. Sahoo, R. Younesi, A.P.S. Gaur, R. S. Katiyar and M. J. F. Guinel, J. Mater. Sci. 49 (2014) 5899.

[23] S. Shankara, Y.J. Kalanur, Y. Hwang, O. Chae and J. Shim, J. Mater. Chem. A 1 (2013) 3479.

[24] C. T. Nguyen, T. P. Pham, T. L. A. Luu, X. S. Nguyen, T. T. Nguyen, H. L. Nguyen and D. C. Nguyen, Ceram. Int. 46 (2020) 8711.

[25] G.. Williamson, W.H. Hall, Acta Metall. 1 (1953) 22.

[26] N. Van Thai, N. Tuan Son, L. Thi Lan Anh, P. Van Thang, N. Huu Lam, N. Cong Tu, Proc. 11th Natl. Conf. Solid Phys. Mater. Sci., Qui Nhon Nov. 2019, pp. 632-635.

[27] M. Henry, J. P. Jolivet and J. Livage, Aqueous Chemistry of Metal Cations: Hydrolysis, Condensation and Complexation, (Springer- Verlag, Berlin Germany, 1992) 153-206.

[28] G. N. Kustova, Y. A. Chesalov, L. M. Plyasova, I. Y. Lin and A. I. Nizovskii, Vib. Spectrosc. 55 (2011) 235.

[29] D. Gazzoli, M. Valigi, R. Dragone, A. Marucci and G. Mattei, J. Phys. Chem. B. 101 (1997) 11129.

[30] L. A. T. Luu, T. P. Pham, V. P. Han, V. T. Duong, X. V. Le, T. S. Pham, D. T. Do, V. Dang Duc, H. L. Nguyen, C. T. Nguyen, Vietnam J. Sci. Technol. 56 (2018) 127.

[31] M. Ahmadi, J.-F. Guinel, Acta Mater. 69 (2014) 203-209.

[32] Y. He, Y. Zhao, J. Phys. Chem. C 112 (2008) 61.

[33] M. Ahmadi, R. Younesi, M. J. F. Guinel, J. Mater. Res. 29 (2014) 1424.

[34] Y.-S. Li, Z. Tang, J. Zhang, Z. Zhang, J. Phys. Chem. C 120 (2016) 9750.

[35] T. Sanasi, S. Pinitsoontorn, M. Horprathum, P. Eiamchai, C. Chananonnawathorn, W. Hinchreeranun, J. Met. Mater. Miner. 27 (2017) 6.

[36] A. H. Y. Hendi, M. F. Al-kuhaili, S. M. A. Durrani, M. M. Faiz, A. Ul-hamid, A. Qurashi, I. Khan, Mater. Res. Bull. 87 (2017) 148.

[37] K. Baishya, J.S. Ray, P. Dutta, P. P. Das and S.K. Das, Appl. Phys. A. 124 (2018) 1.

[38] K. V. Kumar, Catal. Commun. 9 (2008) 82.

[39] L. Wang, C. Ma, Z. Guo, Y. Lv, W. Chen, Z. Chang, Q. Yuan, H. Ming and J. Wang, Mater. Lett. 188 (2017) 347.

[40] Y. Subramanian, V. Ramasamy, R.K. Gubendiran, G. R. A. J. Srinivasan, J. Electron. Mater. 47 (2018) 7212.

[41] L. Huang, H. Xu, Y. Li, H. Li, X. Cheng, J. Xia, Y. Xu and G. Cai, Dalt. Trans. 42 (2013) 8606.

[42] J. Singh, A. Arora and S. Basu, J. Alloys Compd. 808 (2019) 151734.

[43] L. Gan, L. Xu, S. Shang and X. Zhou, L. Meng, Ceram. Int. 42 (2016) 15235.

[44] M. B. Tahir, G. Nabi, N. R. Khalid and M. Ra, Ceram. Int. 44 (2018) 5705. 